\begin{tabular}{|c|c|}
\hline $\begin{array}{c}\text { European Association for the } \\
\text { Development of Renewable Energies, Environment } \\
\text { and Power Quality (EA4EPQ) }\end{array}$ & $\begin{array}{c}\text { International Conference on Renewable Energies and Power Quality } \\
\text { (ICREPQ'12) }\end{array}$ \\
Santiago de Compostela (Spain), 28th to 30th March, 2012
\end{tabular}

\title{
Numerical analysis of a modified evacuated tubes solar collector
}

\author{
A. I. Sato, V. L. Scalon and A. Padilha \\ Department of Mechanical Engineering \\ Universidade Estadual Paulista "Júlio de Mesquita Filho" \\ Campus of Bauru - Av. Eng. Luiz Edmundo C. Coube, Bauru - SP (Brazil) \\ Phone: 005514 3103-6000 (ext.6493), e-mail:.pg118226@feb.unesp.br, scalon@feb.unesp.br, padilha@feb.unesp.br
}

\begin{abstract}
The need for renewable energy sources, facing the consequences of Climate Change, results in growing investment for solar collectors' use. Research in this field has accompanied this expansion and evacuated tube solar collector stands as an important study focus. Thus, several works have been published for representing the stratification of the fluid inside the tubes and the reservoir, as well as analytical modeling for the heat flow problem. Based on recent publications, this paper proposes the study of solar water heating with evacuated tubes, their operation characteristics and operating parameters. To develop this work, a computational tool will be used - in this case, the application of computational fluid dynamics (CFD) software. In possession of the implemented model, a numerical simulation will be performed to evaluate the behavior of the fluid within this solar collector and possible improvements to be applied in the model.
\end{abstract}

\section{Keywords}

Computational fluid dynamics, evacuated tube, numerical analysis, solar collector.

\section{Introduction}

The XX century was marked by expansion in the use of fossil fuels due to the discovery of large deposits of coal and oil and reducing operating costs associated with an unrestrained economic growth, therefore, advances in renewable energy, including solar energy, remained limited for a long period until the oil crisis in the 1970s, forcing many countries to review their energy policies as a possible fuel shortages became increasingly close. This scenario produced a growing interest in solar energy - and other energy matrices - along with an advance in the scientific field.

But only in recent years that interest in renewable energy sources acquired a global importance due to the intensification of the problems from the Greenhouse Effect and progress in studies related to Climate Change.

The concern with the effects of these climatic changes led the United Nations to create the Intergovernmental Panel on Climate Changes (IPCC) - with support from United
Nations Environment Programme (UNEP) and World Meteorological Organization (WMO) - to seek and evaluate researches related to changes in global climate. And in 1990, the organization completed the first report, which approached the fact that human activities are contributing to global warming through the emission of greenhouse gases (especially carbon dioxide from the burning of fossil fuels) and issued prospects for the probable effects of global warming on society. Other reports followed, and tried to deal with the influence that global climate changes would have on global lives. It also sought to deal with topics related to alternative energy by analyzing the main energy sources, their costs, benefits and possible actions that would allow their implementation in a competitive manner. [1]. In this field, is inserted the solar energy and its various applications.

Solar energy plays an important role for sustainable development in coming years and represents a large-scale alternative energy employment, especially regarding the use in water heating for domestic use. It should be noticed that the profile of energy consumption comprises demand peaks at certain times of day, particularly at about $7 \mathrm{pm}$, when most of the population are coming home and have a chance to take a bath.

Meeting this demand requires a large energy capacity and able to meet this peak consumption. However, with the use of decentralized solar collectors in domestic usage, this peak would not be so pronounced and public investments needed in energy sector could be shifted to other uses, as example, incentive policies for purchasing such systems and taxes reducing.

The current research in renewable energy indicates a growing interest for solar collectors with evacuated tubes, which has as basic characteristic: low heat loss by convection resulting from the vacuum isolation. With researches focused on developing models that represent the problem of heat transfer of this type of collector, the calculation of performance, and emphasis on numerical simulation of water flow inside the tubes and improvements to increase efficiency. The system is drafted in Fig. 1. 


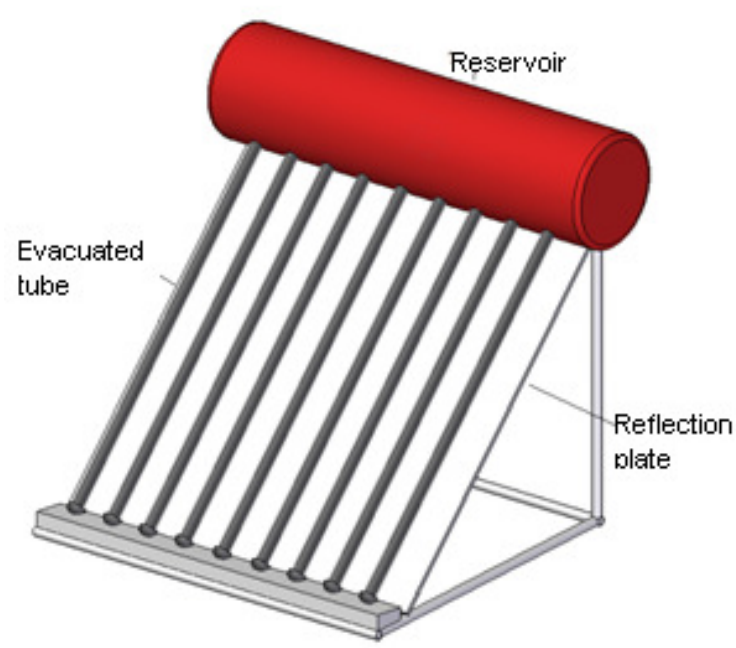

Fig. 1. Schematic view of an evacuated tube solar collector.

Previous works were performed concerning the various ways to extract heat from vacuum enclosed cylinder, including the possibility of developing more realistic methods for calculation of the performance of these collectors. Numerical analysis models were also evaluated for the internal flow of water inside the tube, using the software FLUENT $^{\mathbb{B}}$ for the fluid-thermal solution, allowing the verification of preferential water flows inside the tubes and a stagnation region at the end of large length pipes; which could directly influence the efficiency of the collector. [2]

In additional studies, the natural circulation rate within an evacuated tube was analyzed by using a numerical model and Computational Fluid Dynamics software (CFD), in this case FLUENT $^{\mathbb{B}}$. The modeling of the system consisted of a tube attached to the thermal reservoir. As for the distribution of radiation along the circumference, it was applied the condition of 82 [W] of total energy inserted into the system through uniform or variable heating between the top and bottom of the tube. In conclusion, experimental tests allowed validating the numerical model. [3]

Analysis of an evacuated tube solar collector with single opening and mounted on a reflective system were also evaluated. This system would allow the concentration of the reflected radiation on the collector. The study was conducted by means of numerical model and experimental apparatus. It was also studied the effects on the internal flow by varying the heat flux distribution along the pipe circumference. [4]

A different geometry was also discussed through an evacuated tube collector with two opened ends, arranged vertically and the collector subjected to solar radiation from all directions. [5]. Other studies concerning the analysis of solar collectors must be pointed out, such as [6], [7], [8] and [9]. In this context, the evacuated tube collectors are interest systems whose low heat loss by convection and high efficiency along the day allow the installation of a few units to meet a family necessity for hot water. Therefore, any research that seeks improving the technology and knowledge in such equipment should be encouraged.

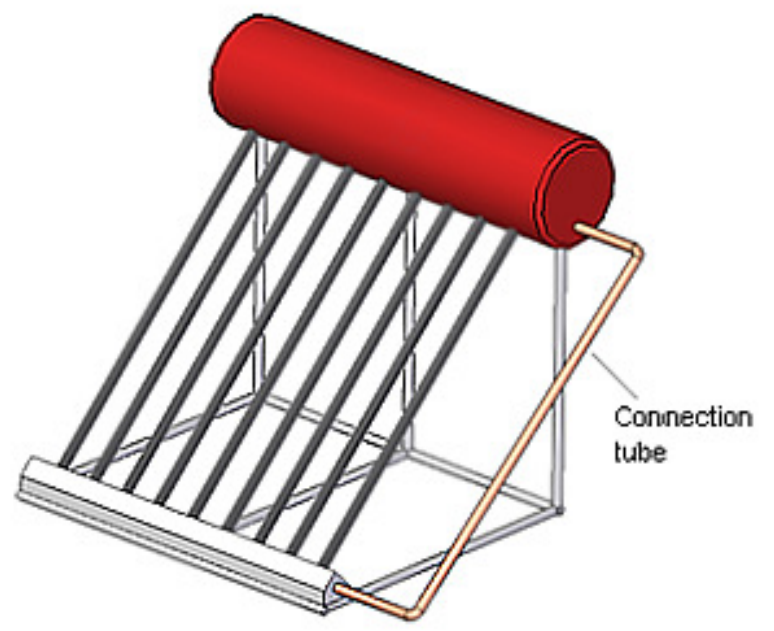

Fig. 2. Schematic view of an evacuated tube solar collector with modified geometry.

The objective of this work is to complement the studies cited earlier, approaching the transient analysis of an evacuated tube collector with modified geometry, to allow better heat removal from the tube and avoid effects such as internal recirculation and stagnation of cold water. The modified model consists in incorporating an evacuated tube with two open ends on a thermosiphon system, represented in Fig. 2. In this case, two geometric approaches are studied concerning the performance and operation of the equipment. For the fluid-thermal analysis of the system, Computational Fluid Dynamics (CFD) and Computational Heat Transfer (CHT) - adopting the ANSYS-CFX $^{\circledR}$ software - will be applied.

\section{Numerical approach}

Three-dimensional models were developed considering only the water in the shape of the storage and pipe. Since the modeling of glass and other components would result in increased computational cost without adding considerable accuracy to the solution. The heat transfer by radiation was modeled by applying a heat flux incident on the lateral surface of the tube. Other approach used was considering only a part of the storage tank and one tube, instead of the entire solar collector.

The problem presented in this fluid-thermal analysis consists in solving the combined equations of NavierStokes and energy equation for incompressible fluid and subjected to density variation with temperature. For this case, ANSYS-CFX ${ }^{\circledR}$ uses the finite volume method for modeling the constitutive equations of the system in their conservation form. The buoyancy problem approach is done by using a source term, expressed in (1), added to the momentum equations by applying the Boussinesq Approach, shown in (2). Which considerers the independence of the fluid density with respect to temperature and pressure, and applies gravitational acceleration gradients on each finite volume as a linear function of the material thermal expansivity; this approach gives good results when used in most incompressible fluids, such as water. 


$$
\begin{gathered}
S=\left(\rho-\rho_{\text {ref }}\right) \mathrm{g} \\
\left(\rho-\rho_{\text {ref }}\right)=\rho_{\text {ref }} \beta\left(T-T_{\text {ref }}\right)
\end{gathered}
$$

Where $S$ is the source term, $\mathrm{g}$ is the gravitational acceleration, $\rho$ is the corrected density, $\rho_{\text {ref }}$ is the reference density used in all terms related to the density except the above source term, $\beta$ is the thermal expansivity, $T$ is the studied temperature and $T_{r e f}$ is the reference temperature set as an average value of the problem domain.

For the buoyancy case, the equations of momentum neglect the hydrostatic gradient from the pressure term, called in this case as "movement pressure" which is responsible for the fluid motion and corrects the absolute pressure to evaluate the material properties.

In this study, the initial temperature of the water in the models was set as $300[\mathrm{~K}]$, the uniform heat flux applied on the tube surface was $500\left[\mathrm{~W} / \mathrm{m}^{2}\right]$, and three different tilt angles was evaluated; $30^{\circ}, 45^{\circ}$ and $60^{\circ}$. The analysis consists in a transient state, so that 1 hours of operation was considered. The gravitational acceleration was set as $9.81\left[\mathrm{~m} / \mathrm{s}^{2}\right]$, absolute pressure $1[\mathrm{~atm}]$ and heat losses was neglected in the models. The fluid motion was considered as laminar flow, since water velocity didn't achieved greater magnitudes.

Through previous analysis, it was observed that the conventional model (shown in Fig. 3), with a single-end tube, has two water flows moving in opposite directions inside the tube and therefore disfavors the extraction of thermal energy. This adverse effect becomes visible when checking the presence of a recirculation region near the inlet where the heated water mixes with the cold water coming from the reservoir and creates a turbulence region. Another unfavorable characteristic is the presence of a stagnation region in the storage tank when it is subjected to small inclinations. [10]. Currently, for these cases, the tube is deviated from the tank centerline, reducing the effect mentioned above. However, this deviation is limited to a maximum because of design purposes and still does not reach perfect functionality. Considering that, two geometries were proposed using an evacuated tube with double opening. The geometries are represented in Fig. 4 and Fig. 5. The original tube length remains the same but a pipe connection was created, joining the tube extremity with the thermal storage device.

The models geometric characteristics are: tube diameters 34 [mm], tube length 1400 [mm], tank diameter 350 [mm] and tank width $150[\mathrm{~mm}]$. The geometries are modeled with tetrahedron elements and five prismatic elements layers placed in specific areas of the models. Crosssection views of the tube and tank-tube connection are presented in Fig. 6. In the modified geometry models, the wall function of the connection tubes is set as free slip because otherwise the pressure loses would be overestimated. The lateral walls of the tank were set as free slip, except the wall which is attached the lateral pipe connection. Because of the physical characteristics of the conventional geometry and the modified geometry with inferior connection, a symmetry plane was used, reducing the number of element, practically, by half. No such approach was possible with the model presented in Fig. 4.

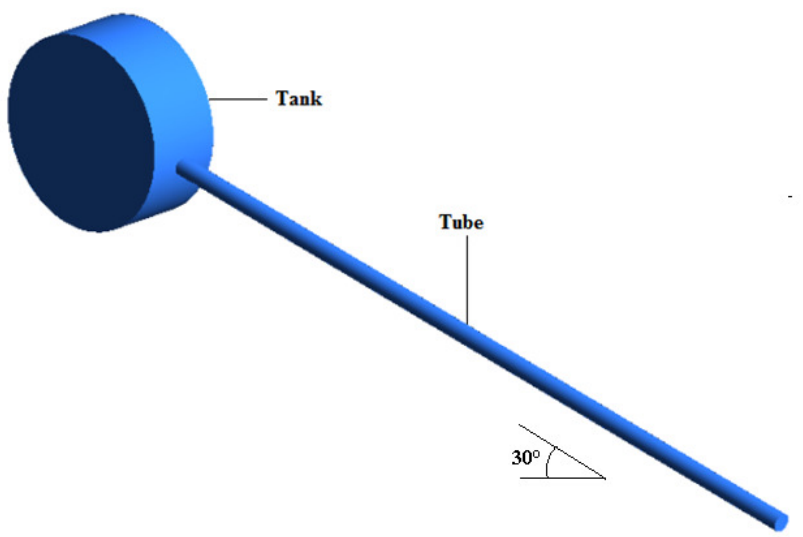

Fig. 3. Model of the conventional solar collector.

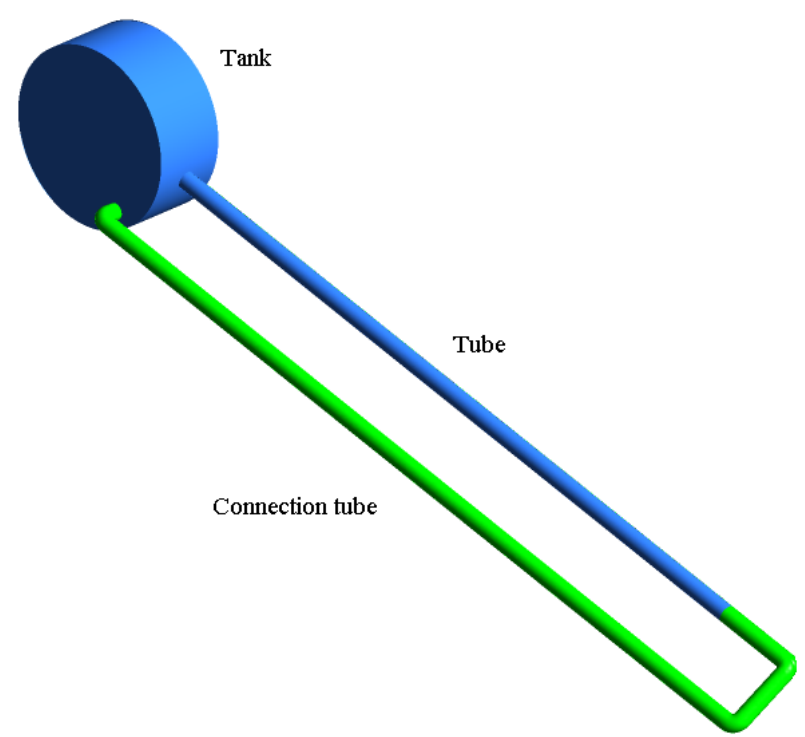

Fig. 4. Model of the modified solar collector with lateral connection.

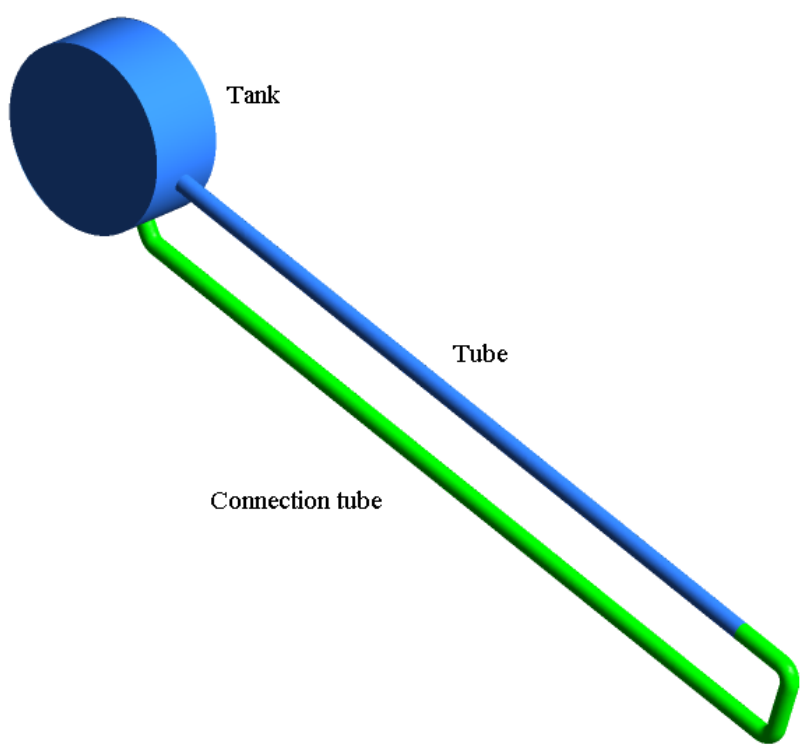

Fig. 5. Model of the modified solar collector with inferior connection. 


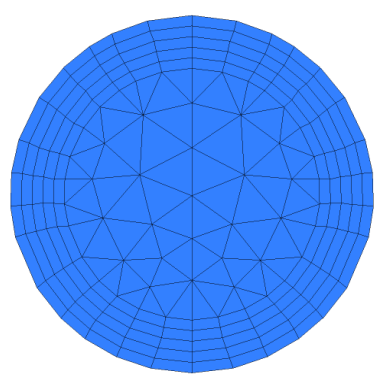

(a)

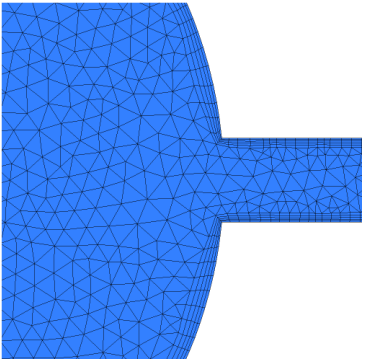

(b)
Fig. 6. Mesh of the (a) tube cross-section and (b) tank and tube junction.

\section{A. Conventional collector geometry}

As previously expressed, the conventional solar collector subjected to small tilt angles, creates a stagnation region inside the storage tank and where cold water is kept unavailable for heating. After simulating 1 hour of operation, it is already possible to visualize the water heating profile and thermal stratification in a conventional solar collector with $30^{\circ}$ tilt angle.

In Fig. 7, the blue region represents water at $300[\mathrm{~K}]$ that was not heated and the red region indicates the highest temperatures of the system, close to the tube wall which receives the heat flux. The recirculation zone is shown in Fig. 8 and a detailed view of the two water flows inside the tube is expressed in Fig. 9.

\section{Results}
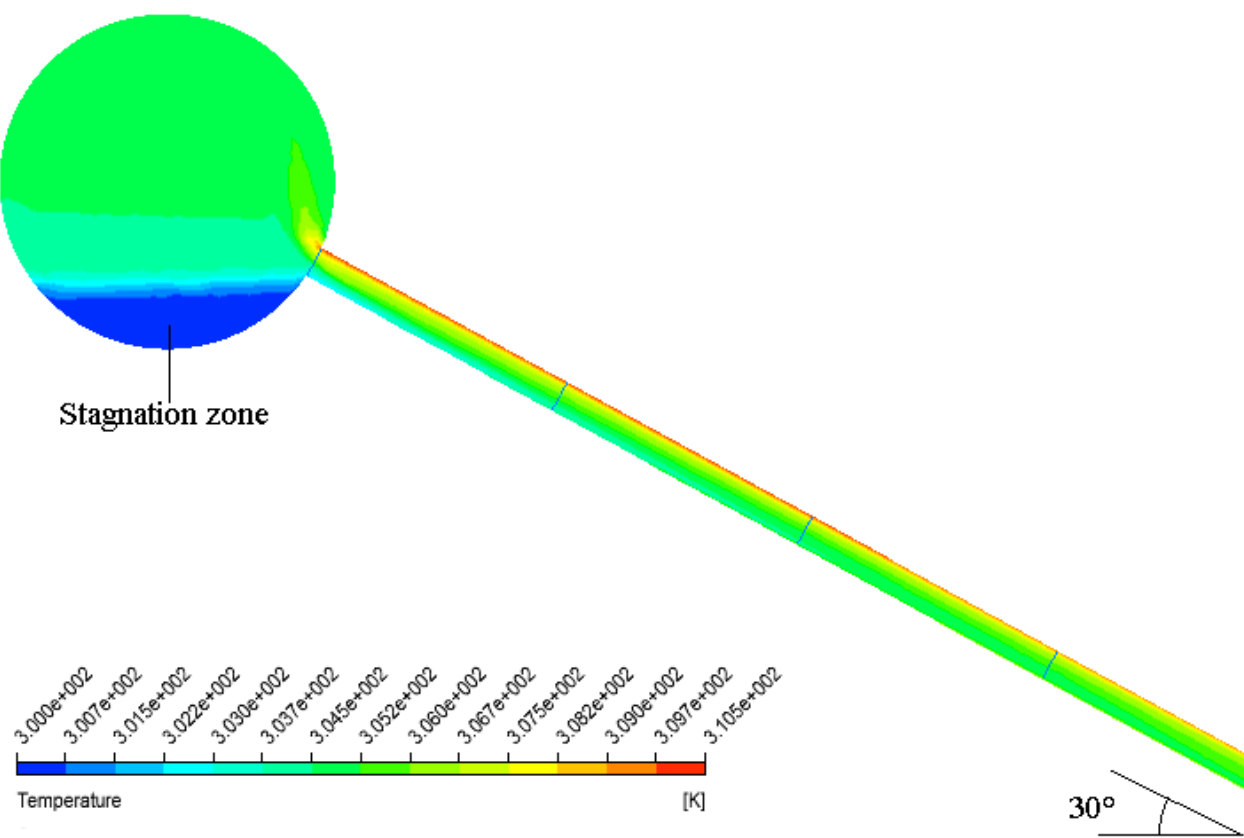

Fig. 7. Temperature distribution of the conventional solar collector after 1 hour of operation.

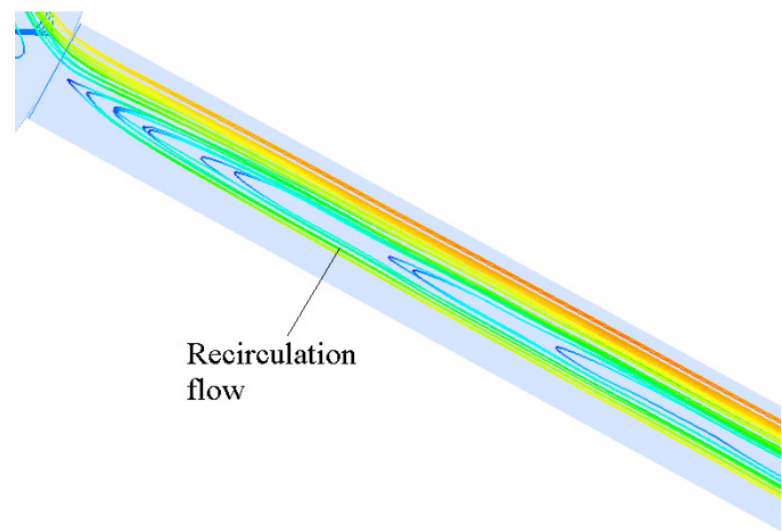

Fig. 8. Recirculation inside the tube. 


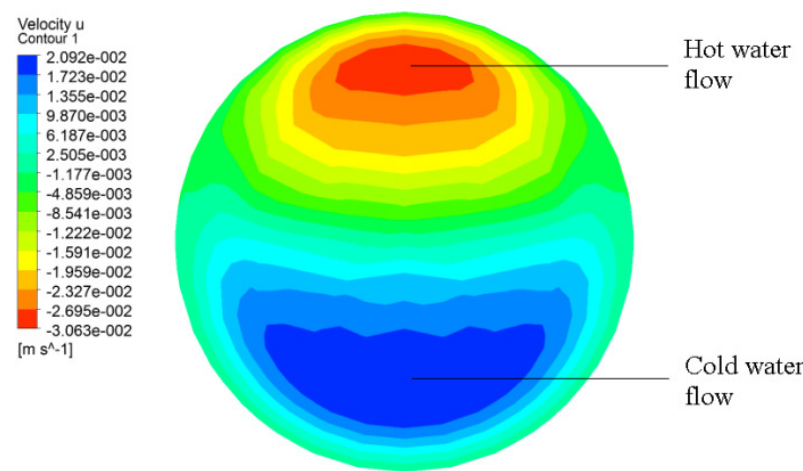

Fig. 9. Temperature distribution inside the tube.

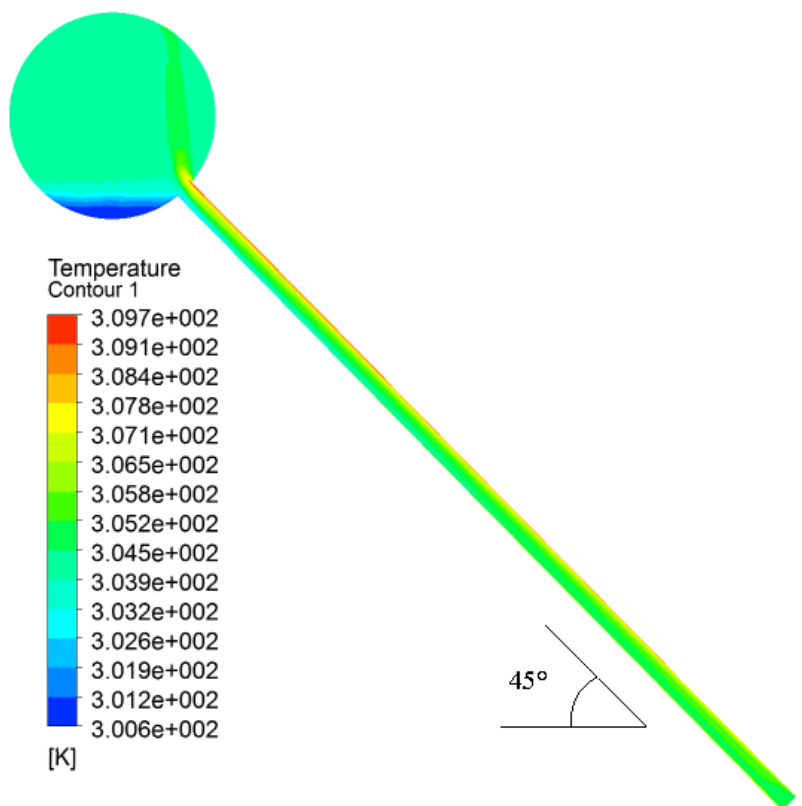

Fig. 10. Temperature distribution of the conventional solar collector after 1 hour of operation with tilt angle of $45^{\circ}$.

At $45^{\circ}$ of tilt angle (Fig. 10), the stagnation area is still present but with less intensity as seen at $30^{\circ}$, and at $60^{\circ}$ the region became negligible. The recirculation zone remains even at higher tilt angles and the water velocity increases the more vertical it is set the solar collector. This occurs based on the importance of the buoyancy component to higher tilt angles.

\section{B. Modified collector geometry with lateral connection}

The model with lateral connection presented an elevated turbulence inside the reservoir, which depreciates the thermal stratification, reducing the collector thermal performance. Another difficult presented was the fact that the stagnation zone became resigned to the connection position. As seen in Fig. 11, the stagnation zone was reduced and the lower temperature observed in the simulation of 1 hour of operation was approximately $302.9[\mathrm{~K}]$, indicating that there was not water at $300[\mathrm{~K}]$ in the system. The recirculation zone was not present but still the higher temperature in the model was lower than in the conventional collector. This can be explained by the fact that the amount of cold water was increased, since there is only one water flow direction inside the tube and the connection tube added more water to the system.

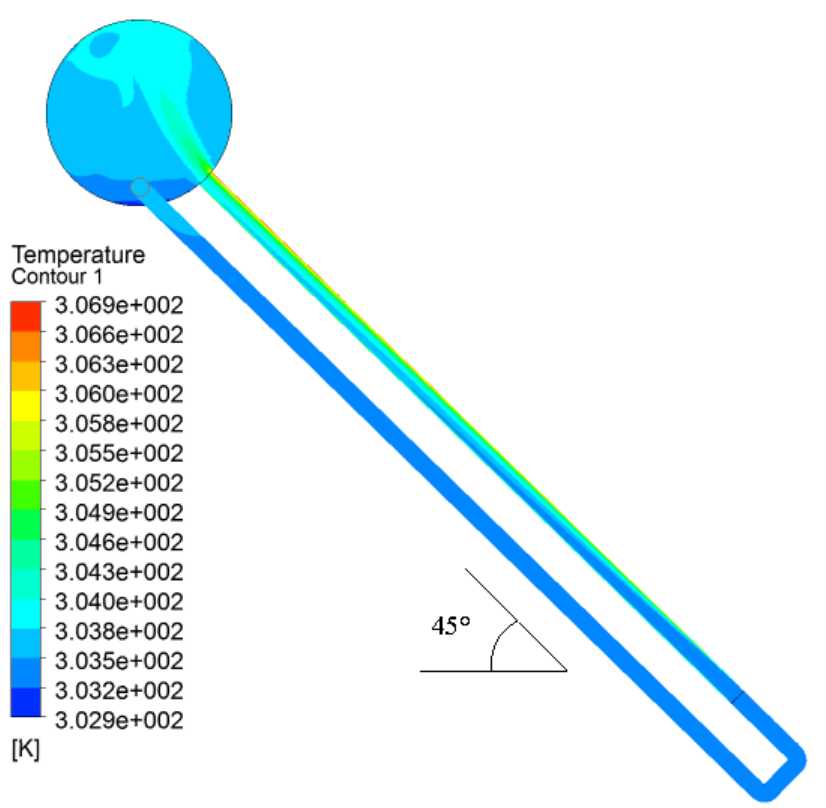

Fig. 11. Temperature distribution of the modified solar collector with lateral connection after 1 hour of operation.

\section{Modified collector geometry with inferior connection}

The inferior connection also creates turbulence inside the reservoir, but in this case with less intensity. The direct effect from this, is the slightly higher temperature achieved in the system, when compared with the lateral connection model with the same tilt angle and simulation time. For the tilt angle of $45^{\circ}$, the maximum temperature in the model was of $307.2[\mathrm{~K}]$, the model with lateral connection achieved $306.9[\mathrm{~K}]$ and the conventional model $309.7[\mathrm{~K}]$. All temperature values were obtained near the wall subjected to heat flux and close to the tank and tube junction. The recirculation and stagnation zones do not exist in the modified systems and only one main flow direction was developed inside the tube. The temperature distribution is shown in Fig. 12.

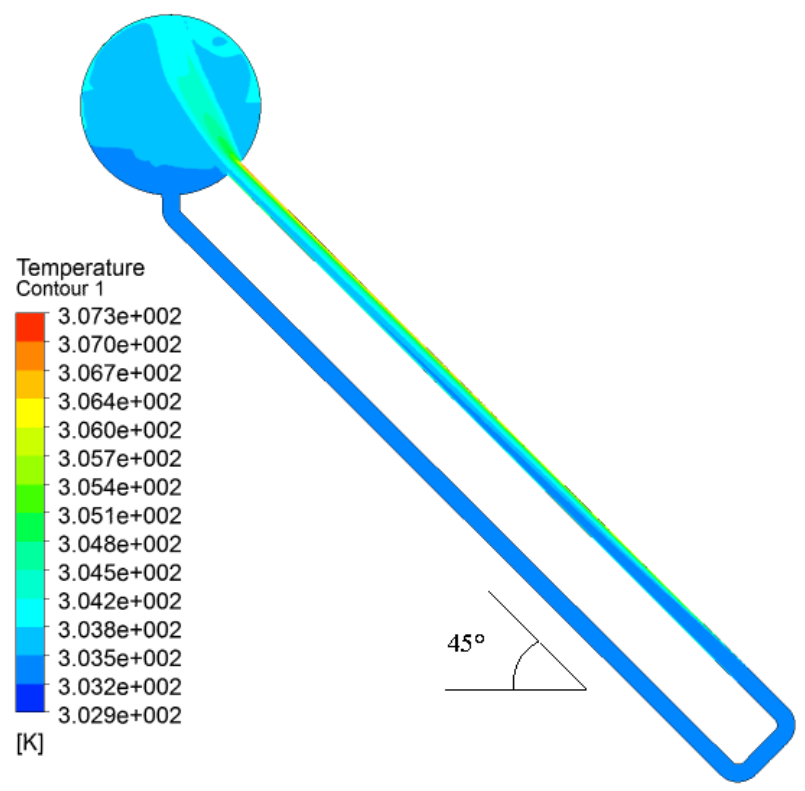

Fig. 12. Temperature distribution of the modified solar collector with inferior connection after 1 hour of operation. 


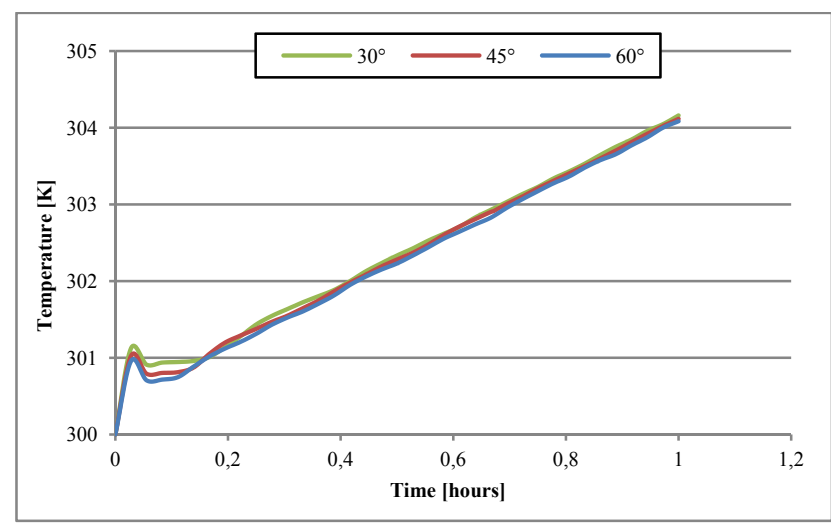

Fig. 13. Temperature development for different inclinations.

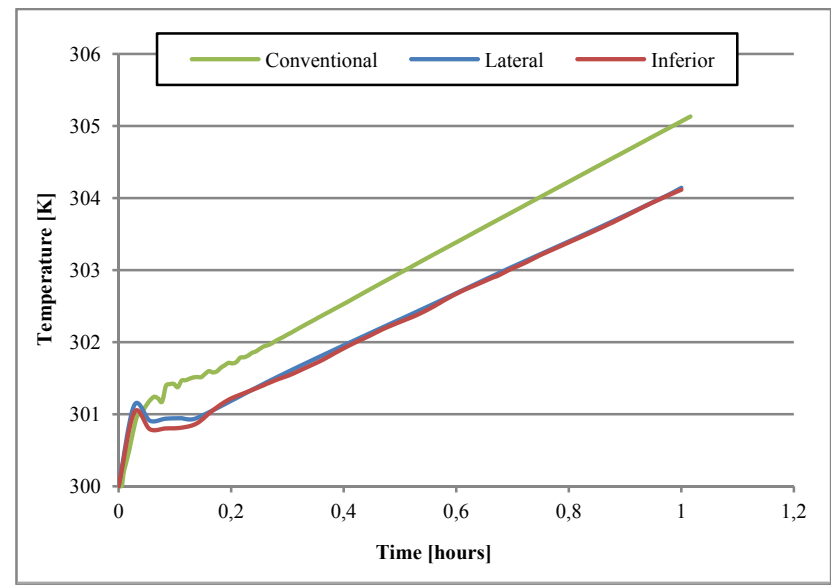

Fig. 14. Temperature development for different geometries with $45^{\circ}$ of tilt angle.

Comparing the thermal performance of the model with inferior connection, subjected to different collector inclinations, the results showed little difference between the temperatures development achieved on each analysis (as can be seen in Fig. 13). The temperatures were measured at the tank and tube connection.

Analyzing the temperature for the three models, the conventional collector acquired higher temperature values. Meanwhile, the two modified collectors presented similar behaviors in temperature development, but the modified geometry with inferior connection obtained temperature magnitudes slightly higher than the other model through the 1 hour of simulation. The temperature development can be seen at Fig. 14.

\section{Conclusion}

The models created to represent the conventional collector and two geometry modifications achieved good results, allowing the solution of the fluid and thermal problem related to an evacuated tube solar collector, and indicating that the employment of modified solar collector geometry might produce superior results with thermal performance. The double-ended evacuated tube operated in a thermosiphon system and the geometry modification solved the problems with water stagnation inside the thermal storage tank; as the lateral connection creates high turbulence inside the thermal storage, the inferior connection seems more feasible to reduce the water mixing inside the tank. But the temperatures achieved in the new models were lower than the conventional collector and, compared with each other, the inferior connection showed a faster heating process and consequently higher temperature at the end of the studied time interval. The water flow inside the tube developed as a single direction flux and consequently the recirculation zone disappeared, preventing that heated water was mixed with cold water. Some improvements might be applied at the new geometries, such as a baffle inside the reservoir to reduce the water turbulence and lead to better thermal stratification; other enhancements are the use of an evacuated tube with a smaller diameter to allow a higher temperature heating and a flat-plate solar collector coupled at the connection tube to substitute the reflection plate and actuate as a pre-heating mechanism.

\section{References}

[1] R. E. H. Sims, R. N. Schock, A. Adegbululgbe, J. Fenhann, I. Konstantinaviciute, W. Moomaw, H. B. Nimir, B. Schlamadinger, "Energy Supply", in Climate Change 2007: Mitigation. Contribution of Working Group III to the Fourth Assessment Report of the Intergovernmental Panel on Climate Change, Cambridge, United Kingdom and New York, USA: B. Metz, O. R. Davidson, P. R. Bosch, R. Dave, L. A. Meyer, 2007.

[2] G. L. Morrison, I. Budihardjo, e M. Behnia, "Water-in-glass evacuated tube solar water heaters", Solar Energy, vol. 76, $n^{\circ} .1-3$, p. 135-140, 2004.

[3] G. L. Morrison, I. Budihardjo, e M. Behnia, "Measurement and simulation of flow rate in a water-in-glass evacuated tube solar water heater", Solar Energy, vol. 78, n. 2, p. 257-267, fev. 2005.

[4] I. Budihardjo, G. L. Morrison, e M. Behnia, "Natural circulation flow through water-in-glass evacuated tube solar collectors", Solar Energy, vol. 81, nº.12, p. 1460-1472, dez. 2007.

[5] L. J. Shah e S. Furbo, "Vertical evacuated tubular-collectors utilizing solar radiation from all directions", Applied Energy, vol. 78, nº. 4, p. 371-395, ago. 2004.

[6] L. J. Shah e S. Furbo, "Theoretical flow investigations of an all glass evacuated tubular collector", Solar Energy, vol. 81, $\mathrm{n}^{\mathrm{o}} .6$, p. 822-828, jun. 2007.

[7] F. O. Gaa, M. Behnia, S. Leong, e G. L. Morrison, "Numerical and experimental study of inclined open thermosyphons", International Journal of Numerical Methods For Heat \& Fluid Flow, vol. 8, n'. 7, p. 748-+, 1998.

[8] Z. Y. Li, C. Chen, H. L. Luo, Y. Zhang, e Y. N. Xue, "Allglass vacuum tube collector heat transfer model used in forced-circulation solar water heating system", Solar Energy, vol. 84, nº. 8, p. 1413-1421, ago. 2010.

[9] R. Tang, Y. Yang, e W. Gao, "Comparative studies on thermal performance of water-in-glass evacuated tube solar water heaters with different collector tilt-angles", Solar Energy, vol. 85, nº. 7, p. 1381-1389, jul. 2011.

[10] A. I. Sato, V. L. Scalon, A. Padilha, "Análise numérica de coletor solar com tubo evacuado", Actas do X Congresso Ibero-americano em Engenharia Mecânica - CIBEM10, 2011. Porto - Portugal: R.M. Natal Jorge. 